\title{
Implant Failure - Prosthodontist's Eye View
}

\author{
Reddy Priyadarshini \\ Department of Prosthodontics, GSL Dental College, Lakshmi Puram, Rajahmundry - 533 104, Andhra Pradesh, India
}

Email for correspondence: pr251184@gmail.com

\begin{abstract}
With the concept of osseointegration, success of implants has drastically increased. This created awareness among the patients who wanted the edentulous site to be replaced with an implant. As said success and failure go hand in hand, failure after successful osseointegration of the implant results in psychological disturbance to the patient as well as the clinician, which adds additional procedures, duration, as well as cost. The present article gives a view over the prosthodontic considerations.
\end{abstract}

Key words: Classifications, evaluation, fractures, implant failures, osseointegration

\section{INTRODUCTION}

Over the decades, dentistry has emerged into a field with various scopes in treatment modalities. One among them is implant dentistry, though evidence of use and success were reported since $\mathrm{AD}$ 600 , the surge in implants for tooth replacement increased from middle of the $1900 \mathrm{~s}^{[1]}$

Dental implant is a prosthetic device made of alloplastic material(s) implanted into the oral tissues beneath the mucosal or/and periosteal layer, and on/or within the bone to provide retention and support for a fixed or removable dental prosthesis; a substance placed into or/and on the jaw bone to support a fixed or removable dental prosthesis (glossary of prosthodontic terms - 8). ${ }^{[2]}$

Implant failure is the inadequacy of host tissue to establish or maintain osseointegration. It is the failure of the implant due to mechanical or biological reasons. ${ }^{[3]}$ Any prosthesis which does not serve the purpose such as function, phonetics, and esthetics can be termed a failure. ${ }^{[4]}$

Awareness regarding implants among the general population has increased to a level where patients directly approach the dentist asking for

\begin{tabular}{|l|l|}
\hline Quick Response Code & Article Info: \\
\hline doi: 10.5866/2018.10.100047 & $\begin{array}{l}\text { Received: 02-01-2018 } \\
\text { Revised: } 25-01-2018 \\
\text { Accepted: 07-02-2018 } \\
\text { Available Online: } 15-04-2018,2017 \text { (www. } \\
\text { nacd.in)(C NAD, 2017 - All rights reserved }\end{array}$ \\
\hline
\end{tabular}

tooth replacement using implant. With a predictably high success rates reported for implant-supported restorations, failures that require removal of implants do occur, which affects the clinician and the patient.

In the present scenario, where implant dentistry is to be practiced through interdisciplinary approach, there were cases where implant is placed, and after osseointegration, the prosthodontist is called for prosthesis/crown placement. If any failure arises, then it is simply called the prosthodontic failure. Is it really a failure due to the prosthesis and the prosthodontist? The present article briefs the prosthodontic considerations for implant failure.

\section{CLASSIFICATION OF IMPLANT FAILURE}

Implant failures are classified based on the time of failure, etiology, origin of infection, condition of failure, supporting tissue type, and according to osseointegration concept.

\section{According to Esposito .[5]}

1. Biological failure:

Early or primary - inadequacy of the host tissue to establish or to maintain osseointegration

Late or secondary - failure to maintain the achieved osseointegration.

2. Iatrogenicfailure-stableandwellosseointegrated but cannot be loaded due to error in positioning the implant and damage to underlying nerves.

3. Mechanical failure - implant fractures, fracture of the screws, and bridge framework. 


\section{According to Truhlar, Tonetti, and Schmid ${ }^{[6]}$}

Early failure - failure within 3 months of implant placement which may be due to altered healing process.

Late failure - after 3 months of implant placement.

According to Askary ${ }^{[3]}$

According to aetiology.

\section{FAILURES BECAUSE OF HOST FACTORS}

- Medical status - osteoporosis and any other bone diseases; uncontrolled diabetes.

- Habits - smoking and parafunctional habits.

- Oral status - poor oral hygiene maintenance, juvenile, and acute periodontitis, and irradiation therapy.

\section{RESTORATIVE PROBLEMS}

- Excessive cantilever, pier abutments, no passive fit, improper fit of the abutment, improper prosthetic design, and improper occlusal scheme, bending moments, connecting implants to natural dentition, premature loading, and excessive torquing are restorative problems that may lead to the implant failures.

\section{SURGICAL PLACEMENT}

- Off-axis placement (severe angulation)

- Lack of initial stabilization

- Impaired healing and infection because of improper flap design or others

- Excess heat generated during bone drills

- Inadequate irrigation

- Minimal space between implants

- Placing the implant in immature bone-grafted sites

- Contamination of the fixture before placement

\section{IMPLANT SELECTION}

- Improper implant type in improper bone type.

- Length of the implant (too short, crown-implant ratio unfavorable)

- Diameter of the implant

\section{According to origin of infection}

- Peri-implantitis - infective process and bacterial origin

- Retrograde peri-implantitis - traumatic occlusion origin, non-infective, forces off the long axis, premature, or excessive loading.

\section{According to timing of failure}

- Before Stage II (after surgery)
- At Stage II (With healing head and or abutment insertion)

- After restoration.

According to condition of failure (clinical and radiographic status)

- Ailing implants - bone loss with deeper probing depth but stable at 3-4 months.

- Failing implants - bone loss, increased probing depth, bleeding on probing, and signs of inflammation but no mobility

- Failed implants - clinical mobility, peri-implant radiolucency, and dull sound when percussed.

- Surviving implants.

According to responsible personnel

- Dentist (oral surgeon, prosthodontist, and periodontist)

- Dental hygienist

- Laboratory technician

- Patient.

\section{According to failure mode}

- Lack of osseointegration (usually mobility)

- Unacceptable esthetics

- Psychological problems.

\section{According to supporting tissue type}

- Soft tissue problems (lack of keratinized tissues, inflammation, etc.)

- Bone loss (radiographic changes, etc.)

- Both soft tissue and bone loss.

Heydenrijik ${ }^{[4]}$ - occurrence in time

- Early failures - Osseointegration has never been established, thus representing an interference with healing process.

- Late failures-Osseointegration not maintained implying processes involving loss of osseointegration

- Soon late failures - Implants failing during the $1^{\text {st }}$ year of loading.

- Delayed late - Failure's implants failing in subsequent years.

\section{CRITERIA TO EVALUATE THE FAILURE OF AN IMPLANT ${ }^{[7]}$}

\section{Schnitman and Schulman criteria (1979)}

- Mobility $<1 \mathrm{~mm}$ in any direction

- Radiologically observed radiolucency graded, but no success criterion defined

- Bone loss no greater than one-third of the vertical height of the bone 
- Gingival inflammation amenable to treatment; absence of symptoms and infection, absence of damage to adjacent teeth, absence of paresthesia and anesthesia or violation of the mandibular canal, maxillary sinus, or floor of the nasal passage

- Functional service for 5 years in $75 \%$ of patients.

Crainin, Silverbranch, Sher, and Salter Criteria (1982)

- In place 60 months or more

- Lack of significant evidence of cervical saucerization on radiographs

- Freedom from hemorrhage according to Muhleman's index

- Lack of mobility

- Absence of pain or percussive tenderness

- No pericervical granulomatosis or gingival hyperplasia

- No evidence of a widening peri-implant space on radiograph

McKinney, Koth, and Steflik Criteria (1984)

Subjective criteria

- Adequate function

- Absence of discomfort

- Patient belief that esthetics and emotional and psychological attitudes is improved.

\section{Objective criteria}

- Good occlusal balance and vertical dimension

- Bone loss no greater than one-third of the vertical height of the implant, absence of symptoms, and functionally stable after 5 years

- Gingival inflammation vulnerable to treatment

- Mobility of $<1 \mathrm{~mm}$ buccolingually, mesiodistally, and vertically

- Absence of symptoms and infection associated with the dental implant

- Absence of damage to adjacent tooth or teeth and their supporting structures

- Absence of paresthesia or violation of mandibular canal, maxillary sinus, or floor of nasal passage

- Healthy collagenous tissue without polymorphonuclear infiltration.

\section{Success criterion}

- Provides functional service for 5 years in $75 \%$ of implant patients.

\section{Albrektsson, Zarb, Worthington, and Erickson G Criteria (1986)}

- Individual unattached implant that is immobile when tested clinically
- Radiograph that does not demonstrate evidence of peri-implant radiolucency

- Bone loss that is $<0.2 \mathrm{~mm}$ annually after the implant's $1^{\text {st }}$ year of service

- Individual implant performance that is characterized by an absence of persistent and/or irreversible signs and symptoms of pain, infections, necropathies, paresthesia, or violation of the mandibular canal

- In context of criteria mentioned a success rate of $85 \%$ at the end of a 5 -year observation period and $80 \%$ at the end of a 10 -year observation as a minimum criterion for success.

\section{Esposito M, Hirish JM, and Lekholm Criteria} (1998) $^{[5]}$

- Absence of mobility

- Radiographic marginal bone loss of $<1.5 \mathrm{~mm}$ during the $1^{\text {st }}$ year

- $<0.2 \mathrm{~mm}$ annually after the $1^{\text {st }}$ year

- Absence of pain or paresthesia.

According to time period of failure - Jividen and Misch ${ }^{[8]}$

- Surgical failure

- Osseous healing failure

- Early loading failure

- Late implant failure

- Long-term implant failure.

\section{EVALUATION OF IMPLANT FAILURE}

\section{Clinical signs of failure}

- During the early phase of healing, complications such as swelling, fistulas, suppuration, early/ late mucosal dehiscence's, and osteomyelitis can occasionally be present which can lead to disturbance in osseointegration process. The first sign of failure can be pain or discomfort associated with mobility. Mobility of the implant indicates a fibrous union which clearly dictates removal of implant.

Different types of mobility are as follows:

- Rotation mobility

- Lateral or horizontal mobility

- Axial or vertical mobility

Occasionally, clinically, discernible mobility can be present without distinct radiographic bone changes. Thus, mobility can be considered the vital sign of implant failure.

\section{Radiographic signs of failure}

- According to Alberktsson ., marginal bone loss of $1.5 \mathrm{~mm}$ during the $1^{\text {st }}$ year and $<0.2 \mathrm{~mm}$ yearly 
can be considered as success criteria. ${ }^{[9,10]}$ Whereas a thin perifixtural radiolucency surrounding the entire implant, with increased marginal bone loss and absence of a direct bone-implant contact indicating loss of stability, and an increased marginal bone loss indicates a failed implant

- Percussion-Subdued sound on percussion is indicative of soft tissue encapsulation. A clear crystallization sound suggests good osseointegration.

\section{Prosthodontic considerations for implant failure}

Prosthodontic evaluation begins before implant placement. Preimplant prosthodontic considerations are a vital phase of overall treatment before implant surgery.

Significant risk factor in implant dentistry is biomechanical stress. Its magnitude is directly related to force. As a result, an increase in any dental force factor magnifies the risk of stressrelated complications. ${ }^{[10]}$

\section{Patient force factors to be considered are}

1. Parafunction - Bruxism, clenching, and tongue thrust.

a. Even after successfully placing the implant fixture, early failure or late failure can occur due to parafunction. These failures are more in the maxillary arch compared to the mandibular due to the bone density and also an increase in the moment of force. ${ }^{[11]}$ These conditions must be identified during the early phases of treatment planning.

b. Nadler classified causes of parafunction as follows:[12]

1. Local factors - tooth form or occlusion and soft tissue change as ulcerations or pericoronitis

2. Systemic factors - epilepsy, cerebral palsy, and drug-related dyskinesia

3. Psychological - anxiety and emotional tensions

4. Occupational - professionals such as dentists, athletes, precision workers, and musicians who developed altered oral habits

5. Involuntary - bracing of jaws such as during lifting of heavy objects or sudden stop while driving

6. Voluntary - chewing gum, pipe smoking, and bracing telephone between head and shoulder
2. Crown height space - It is measured from crest of the bone to occlusal plane in posteriors and to incisal edge in anteriors. ${ }^{[13]}$ Ideal crown height space for a fixed implant prosthesis is around 8-12 mm, which includes the biologic width, abutment height (screw retained or cemented), occlusal material strength, esthetics, and hygiene considerations around abutment crowns. ${ }^{[10,13]}$ Increase in this crown height space increases the forces on cantilevered or angled load. Excessive stress can lead to crestal bone loss, screw loosening, occlusal material fracture, prosthesis fracture, or attachment wear and fracture, and implant fixture fracture, thus implant failure.

3. Masticatory dynamics - Muscle mass, gender, exercise, diet, state of dentition, physical status influence the muscle strength, masticatory dynamics, and the maximum bite force. ${ }^{[10]}$

4. Arch position - Forces are more in the posterior molar region which are generated by the masseter and the temporalis where the condyles being the fulcrum. ${ }^{[10]}$

5. Opposing arch - Implant fixed prosthesis do not benefit from proprioception as do the natural teeth. Bite forces increase by 4 times than the natural teeth. Highest forces are generated with implant prosthesis. ${ }^{[14]}$

\section{Preimplant prosthodontic} evaluation includes assessment of ${ }^{[10]}$

\begin{tabular}{ll}
\hline Maxillary anterior tooth & Lip lines \\
position & Maxillomandibular relations \\
Occlusal vertical & Existing occlusion \\
dimension & CHS \\
Mandibular incisal edge & Temporomandibular joint status \\
Maxillary posterior plane & Extraction of hopeless or \\
Mandibular posterior & guarded - prognosis existing \\
plane & teeth \\
& Existing prostheses \\
& Arch form \\
& Natural tooth adjacent to \\
& implant site \\
& Soft tissue evaluation of \\
& edentulous site \\
\hline
\end{tabular}

- Forces on implant - Implant and its component can sustain the forces which are directed along the long axis, but they cannot sustain the offaxial forces as they create stress at the implantbone interface. ${ }^{[15,16]}$

- Cantilever - Restoration of completely edentulous arch with a cantilever fixed prosthesis, the length and width of the implant fixture, quality of the bone, number 
of implants, opposing occlusion, and anterior and posterior spread of implants must be considered. ${ }^{[15,16]}$

- Tripod effect - Greater the tripod, more the resistance to bending, implants placed in a straight line in an edentulous arch, and minimal resistance to bending forces compared to those placed in a tripod.

- Occlusal load on the cantilever, fulcrum line is established in distal-most implant where cantilever is pushed toward the tissue surface and the anterior implants have tension occlusally, thus resulting in bending forces along the fulcrum. ${ }^{[16]}$

Crown-implant ratio - 1:1 ratio acceptable in full-arch restorations as they provide tripod effect. In partially edentulous conditions, 1:2 ratio is more preferable.

- Tooth and implant connection - Implant is firmly anchored to the bone and does not exhibit any mobility, whereas tooth exhibits certain mobility due to periodontal ligament attachment. ${ }^{[10]}$ Hence, the restoration should be completely implant supported rather than connecting the implant to the tooth.

- Occlusal design - Narrow occlusal table and lingualized occlusion with lingual cusps of maxillary contact the central grooves of mandibular are better to prevent bending forces. Lateral forces or off-axial forces result in failure of the implant, so the forces should be diverted along the long axis of the implant. Thus, establishing centric contact over implants and not lateral contact is important.

Prosthetic complications - Impact of occlusal overload on mechanical components ${ }^{[10]}$

\begin{tabular}{ll}
\hline Screw loosening & Attachment wear \\
Component fracture & Attachment fracture \\
Implant body fracture & Denture tooth fracture \\
Acrylic veneer/porcelain & Acrylic base fracture \\
fracture & Opposing prosthesis fracture \\
Framework fracture & Esthetic complications \\
\hline
\end{tabular}

- Improper fit of the abutments and the fixture can create constant tension and lead to abutment screw loosening or fracture. Greater the stress applied to the prosthesis, greater the risk of abutment screw loosening. Cantilevers also increase the risk of abutment screw loosening, as they increase the forces in direct relationship to the length of the cantilever. Greater the crown height attached to the abutment, greater the force applied to the screw, and greater the risk of screw loosening. Higher the hex height, the less stress applied to the screw, and a corresponding lower risk for abutment screw loosening. ${ }^{[17,18]}$

- Fatigue fractures - Based on the number of cycles and intensity of the force, materials undergo fatigue curve. Due to this continuous fatigue prosthesis, screw fractures are observed in fixed partial and complete fixed prosthesis. Abutment screws are usually larger in diameter, and therefore, fracture is less often. Metal framework fractures have been reported in an average of $3 \%$ of fixed complete and overdenture restorations. Implant body fracture has the least incidence. ${ }^{[10,19]}$

- Esthetic complications are categorized as pink-tissue failures and white-tissue failure. ${ }^{[20-24]}$

\begin{tabular}{ll}
\hline Pink-tissue failures & White-tissue failures are \\
Facial recession & related to the \\
Gingival asymmetry & General form of the tooth \\
Papillary deficiency & The outline and volume of the \\
Graying of the gingival & clinical crown \\
tissue & Color (hue and value) \\
& Surface texture \\
& Translucency \\
& Characterization \\
\hline
\end{tabular}

\section{CONCLUSION}

Failure of an implant is not due to one single entity; it has various factors associated. To achieve any success, identifying the various causes of failure and dealing with the failure at an appropriate time is important. It was told, implant placed within the bone in any position can integrate well. When the esthetics and function of the prosthesis are affected, due to the position of the implant, this improperly positioned implant poses a task for the prosthodontist. Prevention of prosthodontic failure of an implant can be best achieved with accurate diagnosis and treatment planning through interdisciplinary approach and through a better understanding about the biomechanics and the forces acting on the implant and the implant components.

\section{REFERENCES}

1. Prashanti E, Sajjan S. Implant failures. Indian J Dent Res 2011;22:446-53.

2. Ferro KJ. The glossary of prosthodontic terms. J Prosthet Dent 2017;117:1-105.

3. El Askary AS, Meffert RM, Griffin T. Why do dental 
implants fail? (Part I) Implant Dent 1999;8:173-85.

4. Heydenrijk K, Meijer HJ, Reijden Vander WA, Raghoebar GM, Vissink A, Stegenga B. Microbiota around root form endosseous implants. A review of the literature. Int J Oral Maxillofac Implants 2002;17:829-39.

5. Esposito M, Hirsch JM, Lekholm U, Thomsen P. Biological factors contributing to failures of osseointegrated ora implants (I) success criteria and epidemiology. Eur J Oral Sci 1998;106:527-51.

6. Truhlar RS. Perimplantitis-causes and treatment. Oral Maxillofac Surg Clin North Am 1998;10:299-308.

7. Taylor TD. Prosthodontic problems and limitations associated with osseointegration. J Prosthet Dent 1998;79:74-8

8. Jividen G Jr., Misch CE. Reverse torque testing and early loading failures help or hindarance? J Oral Implantol 2000;26:82-90

9. Albrektsson T, Zarb G, Worthington P, Eriksson AR. The long-term efficacy of currently used dental implants: A review and proposed criteria of success. Int $J$ Oral Maxillofac Implants 1986;1:11-25.

10. Misch CE. Contemporary Implant Dentistry. $3^{\text {rd }}$ ed St. Louis, MO: Mosby Elsevier; 2008.

11. Jaffin R, Berman C. The excessive loss of branemark fixtures in type IV bone: A 5-year analysis. J Periodontol 1991;62:2-4.

12. Nadler SC. Bruxism, a clinical and electromyographic study. J Am Dent Assoc 1961;62:21-44.

13. Misch CE, Misch-Dietsh F. Dental Implant Prosthetics. St Louis: Mosby; 2005
14. Haraldson T, Carlsson GE. Bite force and oral function in patients with osseointegrated implants. Scand J Dent Res 1977;85:200-8.

15. Robert DM. Oral and Maxillofacial Surgery Clinics of North America-Implant Failures. Philadelphia, PA W. B. Saunders \& Co.; 1998.

16. Dewan SK, Arora A, Sehgal M. Implant failures: A broader perspective. J Dent Implant 2015;5:53-9.

17. Kallus T, Bessing C. Loose gold screws frequently occur in full arch fixed prosthesis supported by osseointegrated implants after 5 years. Int J Oral Maxillofac Implants 1991;9:169-78

18. Boggan RS, Strong JT, Misch CE, Bidez MW. Influence of hex geometry and prosthetic table width on static and fatigue strength of dental implants. J Prosthet Dent 1999;82:436-40.

19. Wiskott HW, Nicholls JI, Belser UC. Stress fatigue: Basic principles and prosthodontic implications. Int J Prosthodont 1995;8:105-16

20. Prudhviraj DR, Raj S. A review on implant failures. J Appl Dent Med Sci 2016;2:183-9.

21. Fuentealba R, Jofre J. Esthetic failure in implant dentistry. Dent Clin North Am 2015;59:227-46.

22. Wheeler SL. Implant complications in the esthetic zone J Oral Maxillofac Surg 2007;65:93-102.

23. Al Sabbagh M. Implants in the esthetic zone. Dent Clin North Am 2006;50:391-407.

24. Butler B, Kinzer GA. Managing esthetic implant complications. Compend Contin Educ Dent 2012;33:514-8. 